\title{
134. RESPECTO DE UN ICONO DESIGNADO COMO AGAVE FILAMENTOSA POR SESSÉ Y MOCIÑO
}

\author{
Daniel GUILLOT \& Piet VAN DER MEER
}

About one picture from Sessé \& Mociño that they named Agave filamentosa.

Palabras clave. Icono, Sessé \& Mociño, A. filifera Salm.- Dyck, A. schidigera Lemaire.

Keywords. Icon, Sessé \& Mociño, A. filifera Salm.- Dyck, A. schidigera Lemaire.

En la obra pictórica de la Expedición a Nueva España de Mociño \& Sessé (1787 1803), encontramos un grabado bajo el nombre de $A$. filamentosa. Se trata de un dibujo que en realidad corresponde a $A$. schidigera Lemaire y que podemos tomar como un lectoicono de esta especie. Vamos a comparar el icono con las descripciones de $A$. schidigera de Irish \& Irish (2000), Thiede (in Eggli, 2001), Breitung (1968) y Gentry (1982) (tab. 2), con las descripciones de otro táxon A. filifera Salm.Dyck, al que numerosos autores consideran como sinónimo de A. filamentosa Salm.-Dyck (Gentry, 1982; Thiede, in Eggli, 2001) (tab. 1), de estos autores, y con el icono correspondiente al neotipo tomado por Gentry (1982) de Lemaire (in Gentry, l.c.), correspondiente a A. filifera (fig. 1), y el lectotipo tomado por este autor de A. schidigera (fig. 2) correspondiente al icono de Lemaire (in Gentry, l.c.). La obra pictórica de Sessé \& Mociño (1787 - 1803), pertenece al Hunt Institute for Botanical Documentation, no habiendo sido publicado hasta el momento.

Ambas especies se encuentran encuadradas en la sección Xysmagave dentro del subgénero Littaea Breitung, 1968; Jacobsen 1954, en el subgénero Littaea grupo Filiferae (Gentry, 1982) Thiede (in Eggli, 2001). A. filifera es bien conocida en la horticultura europea, de carácter clonal, a partir de una o dos introducciones en el siglo XIX. Sánchez Mejorada (1978), la sitúa esporádicamente en Barranca, Metztitlán, sobre basaltos, mientras la especie A. schidigera se distribuye por Méjico, Michoacan, Zacatecas, y Jalisco, según Breitung (1968).

Según Irish \& Irish (l.c.), A. filifera tiene una fuerte tendencia a formar rosetas y en general es ligeramente más grande que $A$. schidigera, la cual tiene filamentos bastos y hojas que son en general más delgadas y flexibles que A. filifera. Numerosos nombres de híbridos y formas han sido utilizadas durante largo tiempo, incluyendo A. $x$ ortiesiana Hort, una forma arbustiva, $A$ x leopoldii Hort ex G. Nicholson (=A. $x$ leopoldii II) un híbrido con A. filifera y A. schidigera var. taylori Jacobson, un nombre no válido aplicado a una forma con hojas más anchas (Irish \& Irish, l.c.).

Thiede (in Eggli, l.c.), incluye dentro de A. filifera, cuatro subespecies, A. filifera subsp. filifera Thiede, A. filifera subsp. microceps Kimnach, A. filifera subsp. multifilifera (Gentry) B. Ullrich y A. filifera subsp. schidigera (Lemaire) B. Ullrich, dentro de la cual incluye A. schidigera.

Para este autor, A. filifera subsp. filifera es separable de la relacionada subsp. schidigera, por su hábito cespitoso, hojas más cortas y gruesas, y flores más pequeñas, con un tubo más corto (Gentry, l.c.). Ullrich (1992) reduce $A$. schidigera y $A$. multifilifera Gentry a subespecies de A. filifera.

Según Gentry (l.c.) A. schidigera aparece estrechamente relacionado con A. filifera, pero se separa por su hábito más largo, más grueso, 


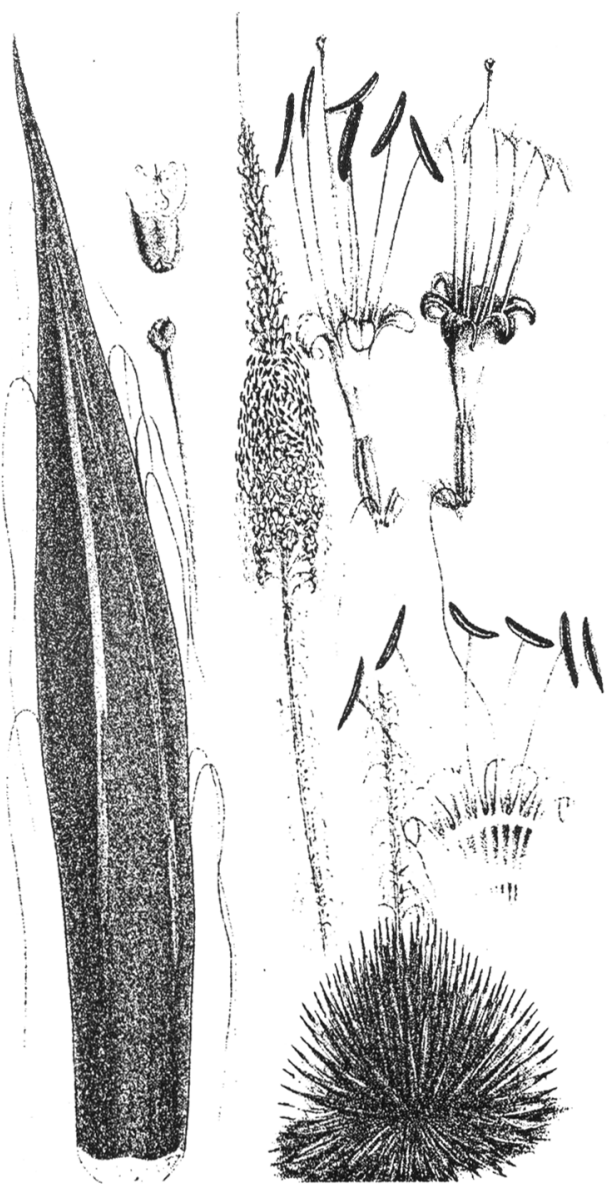

Figura 1. Icono de Lemaire de Agave filifera

hojas más blandas, márgenes más bastos, fuertemente filíferos. Las hojas son variables pero los distintos tipos están dispuestos al azar en varias poblaciones y tan poco localizados que no es práctico delimitar variedades (Gentry, l.c.).

En cuanto al icono de Sessé \& Mociño (l.c.), presenta las siguientes características: Roseta solitaria, simétrica, con tallo corto, regular, ancha, ligeramente mayor anchura que altura, hojas uniformemente extendidas, densamente dispuestas, erectas o ascendentes, lineares, con la anchura máxima en la zona media y atenuadas en la base, rectas o falciformes, como se observa en la hoja grande, de color verde oscuro, lustrosas, lisas, margen liso y numerosos filamentos recurvados toscos; impresiones de hojas jóvenes de color blanco, acuminadas. Espina apical recta o levemente curvada, de color marrón anaranjado. Inflorescencia recta, vástago fuerte, tres veces la altura de la roseta florífera en _ - 2/3 superiores, espiciforme, laxa. Ovario de color verde, elíptico. Corola púrpura o rojiza, estambres exertos con filamento blanco y antera amarilla. Brácteas triangulares estrechas, tubo infundibiliforme. Lóbulos iguales, pedicelos cortos, dicótomos, tépalos lineares, agudos. Cápsulas oblongas, cortamente estipitadas. Espiga ensanchada en la zona superior. Brácteas laxamente dispuestas. Flores ascendentes recurvadas, ovario fusiforme con cuello; tépalos no recurvados.

Si comparamos el icono de Mociño \& Sessé (l.c.) respecto del de Lemaire (in Gentry, l.c.) de A. filifera, en cuanto a la roseta foliar el icono de aquellos presenta menor número de hojas y estas más erectas o erecto-ascendentes, con un pequeño tallo, y es más regular, mientras el icono de Lemaire (in Gentry, l.c.), es más irregular, con un numero muy superior de hojas, presentando las basales tendidas. Respecto de la morfología de las hojas de la roseta de Mociño \& Sessé (l.c.) son más anchas, mientras que la hoja dibujada en solitario es falciforme, mientras las de Lemaire (in Gentry, l.c.) tanto las de la roseta como la solitaria son lineares, coincidiendo en la morfología de la espina apical siendo esta decurrente en el icono de Lemaire (in Gentry, l.c.), dato no observable en el icono de Sessé \& Mociño (l.c.). En cuanto al escapo coinciden en el tamaño relativo, en su disposición erecta, en las numerosas brácteas estrechas que lo recubren, pero se diferencian en la posición de la parte florífera, 2/3-superior en Mociño \& Sessé (l.c.), y aproximadamente $1 / 3$ superior en Lemaire 
(in Gentry, l.c.), muy denso y más o menos cónico en este y estrechado, en Mociño \& Sessé (l.c.) laxo y más o menos oblongo, flores con pedicelo corto en Mociño \& Sessé (l.c.), y claramente pediceladas en Lemaire (in Gentry, l.c.). Similares en cuanto a morfología del ovario, y la corola infundibiliforme, pero los lóbulos en Mociño \& Sessé (l.c.) son filiformes y no recurvados mientras en Lemaire (in Gentry, l.c.) son oblongos y recurvados.

El lectotipo elegido por Gentry (l.c.) para A. schidigera, una ilustración de Lemaire (in Gentry, l.c.) en Illustration Horticole, coincide con el icono de Sessé \& Mociño (l.c.), en el número aproximado, disposición, tamaño relativo relación altura/diámetro, roseta, hojas erectas o erecto - ascendentes, lineares o falciformes, tamaño relativo de la espina, recta o levemente curvada con numerosos filamentos laterales bastos y la máxima anchura foliar en la zona media.

Los ejemplares cultivados como ornamentales de A. schidigera en la Península Ibérica presentan hojas en roseta densa, numerosas, de color verde oscuro lustroso, curvadas, acanaladas, redondeadas en el envés, con margen liso bastamente filífero; filamentos de $2-5 \mathrm{~cm}$ de color blanco y margen fino más o menos traslúcido, blanco amarillento o teñido de marrón, con la anchura máxima en la zona media, ligeramente engrosadas en la base. Espina apical de color marrón rojizo con una banda basal de $1 \mathrm{~mm}$ rojiza seguida de una banda violeta de $1 \mathrm{~mm}$, ligeramente acanalada, y decurrente 1-4 mm, espina de 1-1'3 cm de longitud y $2-4 \mathrm{~mm}$ de anchura.

Como podemos observar en la tabla 2 , el icono coincide con la descripción de $A$. schidigera de Irish \& Irish (l.c.) en los siguientes caracteres: Roseta solitaria, numerosas hojas, tallo corto, lineares, más anchas en la zona media, de color verde oscuro, lustrosas, margen liso, filamentos toscos blancos. Espina terminal marrón, marcas blancas en las hojas. Flores teñidas de púrpura, en los $2 / 3$ superiores. No presenta diferencias observables. Y respecto de la descripción de $A$. schidigera de Thiede (in Eggli, l.c.), coincide en presentar tallo corto, rosetas solitarias, hojas en ocasiones falciformes, más anchas en la zona media, de color verde, con impresiones de las hojas jóvenes, margen blanco, bastamente filífero, con filamentos blancos y espina terminal de color marrón. Inflorescencias laxas, en la mitad superior. Tépalos purpúreos, tubo infundibiliforme, lóbulos iguales. No presenta diferencias. Coincide con la descripción de A. schidigera de Breitung (l.c.) en: Rosetas solitarias, hojas numerosas, uniformemente extendidas, verdes, espina apical marrón, margen entero, numeroso filamentos blancos bastos arrollados marginales, brácteas triangulares, corola rojiza, y con la descripción de $A$. schidigera de Gentry (l.c.) en presentar rosetas solitarias, simétricas, tallo corto, hojas verdes, filíferas, impresas, lineares, más anchas en la mitad, verdes, rectas o falciformes, lisas, acuminadas, margen blanco y filamentos blancos bastos. Espina apical marrón. Brácteas estrechas, laxamente floríferas en la mitad superior del vástago, tubo infundibiliforme, tépalos iguales, teñidos de púrpura, filamentos estaminales claros, anteras amarillas. Cápsulas oblongas cortamente estipitadas.

Respecto de A. filifera de Gentry (l.c.), como podemos observar en la tabla 1 , el icono difiere en formar matas alargadas, roseta densa, hojas lanceoladas, margen finamente filífero, espina grisácea, espiga afilada, densamente florífera, continua, brácteas densamente colocadas, tépalos recurvados, lanceolados en A. filifera, lineares en el icono, filamentos rojizos, blancos en el icono, anteras rojizas, amarillas en el icono. En cuanto a la descripción de A. filifera de Breitung (l.c.) difiere en: rosetas estoloníferas, en el icono rosetas solitarias, filamentos finos, bastos en el icono, estambres púrpura, icono blanco, y respecto de la descripción de Thiede (in Eggli, l.c.), de A. 


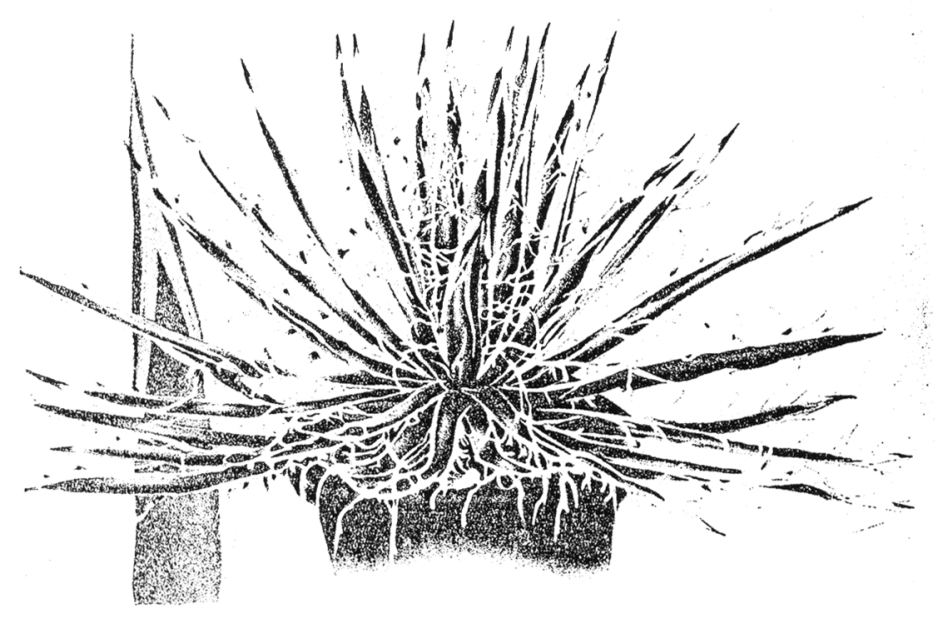

Figura 2. Icono de Lemaire de Agave schidigera

filifera difiere, rosetas densas, solitarias en el icono, hojas lanceoladas, lineares en el icono, margen finamente filífero, basto en el icono, espina grisácea, marrón en el icono, inflorescencia afilada, no así en el icono, floración densa, laxa en el icono.

En cuanto a los ejemplares cultivados como ornamentales en la Comunidad Valenciana coinciden en cuanto a las hojas, dispuestas densamente, color de éstas, verde oscuro lustroso, margen liso y filamentos bastos, anchura foliar máxima en la zona media y espina apical de color marrón.

Coincide completamente con las descripciones de A. schidigera de Irish \& Irish (l.c.) y de Breitung (l.c.), con el lectotipo elegido por Gentry (l.c.) para A. schidigera, y con los ejemplares cultivados como ornamentales en la Comunidad Valenciana, presentando numerosas diferencias respecto de A. filifera de Breitung (l.c.) y Gentry (l.c.), así como respecto del icono de Lemaire de $A$. filifera (in Gentry, l.c.). El icono corresponde a un ejemplar de A. schidigera.

\section{BIBLIOGRAFÍA}

BREITUNG, A.J. -1968- The Agaves. The Cactus and Succulent journal. Yearbook.

EGGLI, U. -2001- Monocotyledons. Illustrated Handbook of Succulent Plants. Springer

GENTRY, H. S. -1982-Agaves of Continental North America. The University of Arizona Press. Tucson.

IRIHS, M. \& G. IRISH. -2000- Agaves, Yuccas \& Related Plants. A. gardener's guide. Timber Press. Portland. Oregon.

JACOBSEN, H. -1954- Handbuch der Sukkulenten Pflanzen. Band I. Jena. Veb Gustav Fischer Verlag.

SÁNCHEZ, F. -1978- Cactáceas y suculentas de la Barranca de Metztitlan. Soc. Mex. Cact. Publ. No. 2. Méjico. D. F. 131 pp.

ULLRICH -1992- On the discovery of A. schidigera Lemaire and status of certain taxa of section Xysmagave Berger. Brit. Cac. Succ. J: 10 (3): $61-70$, ills. Map.

Aceptado para su publicación en julio de 2003

Dirección de los autores. Daniel Guillot Ortiz: Cl. La Pobleta 7. 46118, Serra (Valencia); Piet Van der Meer: Camino Nuevo de Picaña sn. 46014, Picaña (Valencia). 